\title{
WEB 2.0: LITERATURA INFANTIL / JUVENIL E COMUNIDADES INTERPRETATIVAS
}

\author{
Fernando Azevedo (UM) \\ Ângela Balça (UE) \\ Glória Bastos (UAb)
}

Resumo: Este artigo discute como a web potencia a leitura de literatura infantil/juvenil e promove a criação/partilha entre comunidades interpretativas. Problematizamos o lugar desta matriz literária na Academia, o papel da social web na formação literária e cultural dos jovens e o desafio da web na configuração de novos públicos leitores.

Palavras-chave: Web2.0, Leitura, Literatura Infantil/Juvenil, Comunidades Interpretativas, Formação de leitores.

Abstract: This article discusses how the web enhances the reading of children's literature / young adult literature and promotes the creation/ sharing between interpretative communities. It problematizes the place of this literary matrix at the Academy, the role of the social web in literary and cultural education of young people and the web challenge in new readerships.

Key-words: Web2.0, Reading, Children's literature/Young adult literature, interpretative communities, readers development.

\section{O QUE NOS DIZEM OS TEÓRICOS DA ACADEMIA?}

A literatura infantil/juvenil tem sido, desde sempre, objeto de elevada controvérsia. São, com efeito, vários os investigadores que sublinham as dificuldades de definição conceptual (GRIFFITH; FREY, 1992), bem como a ambiguidade dos termos utilizados (HUNT, 1992) ou a relação dos mesmos com determinados códigos culturais historicamente variáveis (NIKOLAJEVA, 1995). Se, no passado, não lhe era reconhecida 
voz e relevância enquanto objeto específico para um certo público leitor (as crianças) (SHAVIT, 2003), a Academia só muito recentemente a reconheceu como espaço efetivo para a iniciação dos mais novos à cultura literária. Todavia, pela sua relação de diálogo íntimo com uma importante dimensão modelizadora dos realia - já que se trata de, pelos seus textos, iniciar a criança no conhecimento da literatura -, ela tem sido, em determinados momentos, lida à luz de um projeto formativo, com o risco de exaurimento da sua natureza intrinsecamente polissémica e plurissignificativa. Deste modo, o grande desafio para a comunidade educativa, aquela que privilegiadamente trabalha com a literatura infantil/juvenil, é entender que esta matriz literária encerra uma função formativa, mas também uma função lúdica. E este é um casamento que nem sempre é compreendido ou tem um final feliz. A natureza intrinsecamente polissémica e plurissignificativa da literatura infantil/juvenil implica que a sua leitura, à luz de um projeto formativo, seja feita de modo a que, de uma maneira lúdica, haja uma exegese do texto e dos valores que ele sempre encerra.

Perry Nodelman (2008, p.2-5), numa obra na qual busca dilucidar o conceito de literatura infantil, socorrendo-se para o efeito, de um conjunto de obras publicadas nos 
últimos 200 anos, e relativamente às quais as comunidades interpretativas não têm dúvidas em as considerar como integrando esse corpus, defende que a noção de literatura infantil depende muito não só daquilo que os leitores consideram como pertencente a esse âmbito, como também da decisão dos editores e, sob o ponto de vista do emissor, da sua ligação a um projecto ou a uma intenção educativa. Mas, de forma pertinente, não deixa de sublinhar que "children's literature is not so much what children read as what producers hope children will read" (NODELMAN, 2008, p.4). Ponto de vista idêntico é também o expresso por John Rowe Townsend (1980, p.197) quando afirma que a decisão depende muito mais dos editores do que dos seus potenciais leitores. Na verdade, o mercado editorial parece ter descoberto, na edição de texto para crianças e jovens, nomeadamente de literatura infantil/juvenil, um enorme filão. Autores que escrevem para os mais novos, autores que até há pouco tempo se dedicavam apenas à literatura para adultos, ilustradores, figuras públicas das mais diversas áreas publicam livros que são catalogados como livros de literatura infantil/juvenil. Não cabendo, neste âmbito, uma reflexão sobre a eventual qualidade destes textos, o que queremos evidenciar é a existência de um mercado, em redor da literatura infantil/juvenil que, 
em Portugal, pelo menos, tem poucas instâncias a regulálo, o que exige dos mediadores de leitura um olhar cada vez mais atento, crítico e competente.

Não obstante estas considerações, é hoje reconhecido à literatura infantil/juvenil um relevante papel na formação dos leitores mais jovens e no seu acesso ao conhecimento da Cultura e da Literatura.

Tendo necessidade de agradar, simultaneamente, a dois públicos leitores diferenciados (os adultos, primeiros mediadores do texto, e as crianças, destinatário secundário desses textos), os seus textos apresentam uma natureza ambivalente, ao preverem dois tipos de leitores-modelo (SHAVIT, 2003).

Ana Maria Machado e Graciela Montes (2003, p.91) sublinham que a literatura infantil é aquela que “(...) puede ser leída también por los niños, y no exclusivamente por los niños. Entonces, seria la literatura que incluye a los niños y no la que excluye a los adultos". De facto, a constituição do corpus da literatura para a infância e a juventude é singular e vai desde, como referimos já anteriormente, os textos que os editores identificam como tal, passando pelos textos aos quais os autores atribuíram essa designação, até aos textos que pertencem 
à designada literatura anexada (CERVERA, 1992), ou seja, textos que integravam a literatura para adultos, mas que o público mais jovem tomou como seus.

Deste modo, a presença da literatura infantil/juvenil na sociedade, e nas instâncias educativas em particular, e o seu reconhecimento pela Academia como sendo uma mais-valia para a entrada das crianças na leitura do mundo, são uma realidade.

\section{O QUE NOS DIZ A SOCIAL WEB ACERCA DA LITERATURA INFANTIL/JUVENIL?}

A internet impôs um novo paradigma nas relações comunicativas. Vivemos hoje sob o signo das gerações hiperconectadas (OTERO, 2014), no âmbito das quais o leitor é frequentemente o construtor de conhecimento, que divulga, para os seus pares, através da social web. Gemma Lluch e Sandra Sánchez (2013) explicitam que o século XXI criou novos cenários para a leitura, o mais importante dos quais aquele que possibilita estabelecer uma comunicação direta entre os que escrevem ou fazem livros e os que os lêem. O espaço web proporcionou à criança e ao jovem também novas formas de comunicar com todos os leitores de uma mesma obra. A partilha, nesta comunidade de leitores virtuais de formas de 
interpretação, mas igualmente da construção de significados individuais, é cada vez mais uma realidade.

No caso concreto da leitura e da literatura infantil/juvenil, o espaço web, com a multiplicação de uma série de "pédias" (a que se associam blogues, salas de chat e outros espaços), não apenas se deslocalizou do espaço tradicional da escola, como também prescindiu da figura tutelar do mediador, aproximando o livro dos seus leitores (SÁNCHEZ GARCÍA; LLUCH CRESPO; DEL RÍO TOLEDO, 2013), aspetos que, complementarmente, contribuíram para uma vulgarização e homogeneização dos traços e características desta literatura.

Cada vez mais no espaço web se multiplicam e se sofisticam as diversas "pédias", nomeadamente relacionadas com a literatura infantil/juvenil, revelando não só a popularidade dessa literatura, mas também a forma integrada como hoje as crianças e os jovens vivem as experiências de leitura, conjugando o livro impresso e as ferramentas da social web. Vejamos o caso da "Potterpédia". Resultante do fenómeno comercial de Harry Potter, a "Potterpédia" surge nas mais diversas línguas, atestando não só o sucesso global da obra de J.K. Rowlling, mas também abrindo a possibilidade de partilha entre leitores de todo o mundo. A "Potterpédia" italiana, por exemplo, recria graficamente a ambiência 
pressentida na saga e coloca à disposição dos leitores um enorme manancial de informações sobre as personagens, sobre o tempo, sobre as mais diversas curiosidades, não faltando múltiplas citações das diversas obras.

Os autores portugueses também se renderam ao espaço web, como forma de comunicar com os seus leitores. Centremo-nos na página da coleção Os Primos, da autoria de Mafalda Moutinho. Para além das mais variadas informações sobre a autora, as personagens, as aventuras, os vídeos de divulgação das obras, esta página apresenta um Clube de Fãs, onde os leitores partilham as suas emoções.

A coleção 7 Irmãos, assinada por Margarida Fonseca Santos e Maria João Lopo de Carvalho, tem associada um blog e uma página no facebook, onde mais uma vez os leitores partilham as suas leituras e as suas opiniões sobre os vários volumes da série. No blog sucedem-se diversas estratégias de marketing ligadas a outras tantas estratégias de promoção da leitura dos livros da coleção junto dos jovens leitores. O blog apresenta várias hiperligações que dão resposta às estratégias referidas anteriormente. Na hiperligação «Afinal, o que é esta coleção?», os leitores encontram uma apresentação detalhada da série e dos temas de cada livro; na hiperligação «Todos os livros - capas e sinopses», surgem links para as capas e sinopses de todas as obras da série. 
Na hiperligação "Os finais dos primeiros livros», os jovens leitores podem encontrar o final de cada um dos volumes da série, o que Ihes permitirá continuar a leitura do número seguinte, situando-se e compreendendo perfeitamente a intriga. Parece-nos que esta prática se revelará uma ótima estratégia, não só para promover a leitura dos livros (o leitor não necessitará obrigatoriamente de ler, de imediato, o volume anterior, para compreender a ação), mas também para promover a sua venda. Aliás, através do blog é possível adquirir os livros da série, e esta compra pode ser também potenciada pelo facto do blog apresentar o selo do Plano Nacional de Leitura, símbolo de qualidade das obras na sociedade portuguesa. As estratégias de marketing reconhecem-se igualmente na possibilidade do leitor ler o 1 o capítulo de cada volume e enviá-lo a um amigo, numa partilha de leituras tão valorizada e tão importante na formação de leitores. O marketing e a promoção da leitura andam, deste modo, de mãos dadas, potenciados pelo espaço da web. Os leitores mais novos aderem com facilidade a estas ferramentas que Ihes permitem igualmente dialogar, de forma fácil e rápida, com os autores das obras. Na hiperligação do blog "Os finais dos primeiros livros", registamos, numa entrada, este diálogo: 
Anónimo: 30 de Julho de 2013 às 23:16

Mas o 70 e 8ㅇ livro, dizem para virmos a este blog para ver o resto a história!!!

7 Irmãos: 31 de Julho de 2013 às 10:13

Tens toda a razão, faltava o fim do 7ำ, já actualizámos. Mas o 8 o apenas diz para virem aqui saber mais sobre os 7 irmãos, ok? Ora vê lá bem.

Obrigada pela ajuda, um beijinho da Margarida e da Maria João. (http://7irmaoslivros.blogspot. pt/2013/07/os-finais-dos-primeiroslivros.html)

Por fim, o blog tem a hiperligação «Faz-te nosso amigo no facebook», uma clara evidência de como os mais novos vivem hiperconectados. Da mesma forma, parece-nos que os autores também se movem, apreciam e são motivados pelas partilhas com os seus leitores, agora apenas à distância de um clique, solicitando mesmo a sua opinião para a construção das obras, que registamos nestes comentários:

Vera Gomes: $18 / 8$ às 5:05

Nunca mais sai o próximo livro? E as novas capas?

Margarida Fonseca Santos: 4/9 às 10:49

Nova capa para o livro 4, Maria atravessa o Atlântico - que acham? Ilustração de Miguel Gabriel

(https://www.facebook.com/7irmaos/ timeline?ref=page_internal) 
O espaço web potenciou sobremaneira aquilo que Cláudia Sousa Pereira (2007) denominou como reconfiguração de novos tempos para a infância, que consistem "no contacto com objectos culturais que parecem misturar, de forma incompreensível para os adultos, o lúdico e a leitura" (PEREIRA, 2007, p.66). A literatura infantil e juvenil não foge a esta lógica da comunicação de massas, virtual, onde blogs, jogos de computador, filmes no youtube, que gravitam em torno da obra literária, são avidamente consumidos pelos mais novos.

Assim, tal como Unsworth (2008), podemos também referir que se verificam aqui "complementaridades sinergéticas", na medida em que os mundos narrativos dos livros para crianças e jovens são ampliados e reconfigurados de diversas formas nos média. Também exemplo paradigmático destas sinergias foi o da série Diário de Sofia (de Marta Gomes e Nuno Bernardo) que teve o seu início na web e só depois viria a assumir a forma de livro impresso, com um sucesso assinalável que foi a seguir aproveitado pelos canais televisivos e com impacto a nível internacional. Dos mesmos autores, a coleção de aventuras Bia \& Fred (três volumes editados em 2007), estabelecia uma relação direta entre a leitura e um site na internet (entretanto desactivado com o fim da coleção): o livro ia apresentando pistas para os leitores utilizarem no 
site como forma de descobrir os enigmas propostos. Estas várias situações corporizam, de forma clara, o conceito de "dynamic hybrid book" proposto por Dresang (2008), em que os princípios de interactividade, conectividade e acesso, que ela coloca como principais linhas de força para os livros e a leitura na era digital, surgem amplamente assumidos. As relações entre o impresso e o digital, entre o offline/online, têm-se, de facto, complexificado, influenciando a forma como os jovens leitores se relacionam com a literatura.

\section{OS DESAFIOS DA WEB 2.0 NA CONFIGURAÇÃO DE NOVOS PÚBLICOS LEITORES}

Investigações desenvolvidas em Espanha com adolescentes (MARTÍN-BARBERO, 2011, LLUCH Y ACOSTA, 2012) enfatizam a satisfação dos participantes em tornaremse atores do próprio discurso, ao poderem comunicar uns com os outros graças às ferramentas tecnológicas em espaço web. Outros estudos demonstram que navegar na internet é uma atividade autónoma para os menores, com uma escassa mediação adulta (BRINGUÉ Y SÁBADA, 2011).

Do ponto de vista da leitura e da criação de públicos leitores, as possibilidades criadas pela web trouxeram novas dinâmicas que importa ter em atenção. Um dos principais aspetos relaciona-se com as múltiplas oportunidades que são criadas 
para se interagir com a literatura, nomeadamente através da dimensão multimodal dos textos, que tem vindo a ser aperfeiçoada. O hipertexto e o hipermédia criam situações de leitura diversificadas: ilustrações animadas, possibilidade de "dar voz" às personagens ou de selecionar trechos de música que acompanham a narrativa são algumas das hipóteses que vários produtos trouxeram para a leitura. Naturalmente que as possibilidades interpretativas são ampliadas, por esta via, para outras dimensões - de sinal mais ou menos positivo - que o texto em papel não permitiria (UNSWORTH, 2003). Se, por um lado, a crítica de convite à dispersão, que frequentemente é apontada ao hipertexto, pode ser um problema, por outro lado não se pode negar a abertura compreensiva e interpretativa destes novos contextos de leitura. Contextos que ao conferirem ao leitor um papel mais ativo, numa interação mais direta e imediata com o texto, se aproximam, em certa medida, do jogo electrónico.

Vários exemplos comprovam que não se trata já de apenas ler uma história/um livro, mas de interagir ativamente com ela de diferentes formas. Como atrás se referiu, o entusiasmo com a série Harry Potter deu origem a uma miríade de websites em redor da obra (listadas na página oficial da autora), localizadas nas mais diversas latitudes e em diferentes línguas, revelando o interesse e 
o envolvimento dos leitores. O ciberespaço proporciona assim um palco privilegiado para a reinvenção de tradicionais formas de interação com a obra (por exemplo, o comentário crítico, mais ou menos impressivo), mas, sobretudo, para a partilha de ideias numa escala muito mais alargada. A possibilidade de muitos poderem falar para muitos, comunicando os seus pontos de vista e lendo os de outros, por vezes do outro lado do mundo, permitem esta construção de comunidades de partilha (e porque não, de aprendizagem?) erguendo de uma forma cooperativa múltiplas leituras sobre a obra.

Por outro lado, tal como Beagley (2012) refere, este novo contexto desafia os conceitos de autor, leitor, crítico:

The suddenly ubiquitous social media engendered by Web 2.0, typified by Youtube, Facebook, Twitter, personal blogs and so on, has not just given new tools for expression and open up vast new audiences. Its democratization of the act of creating a text, and presenting it to a wide audience, challenges to the core our long-held definitions of the author, the reader, the critic, the text and, particularly our traditions of learned discourse. (BEAGLEY,2012, s/p)

Esta situação coloca desafios interessantes, a estes vários intervenientes, na medida em que os discursos 
sobre as obras multiplicam-se e cruzam-se, no espaço digital. As comunidades interpretativas são agora mais fluídas (por exemplo, nos vários intervenientes que vão entrando e saindo da "rede"), mas também geradoras de afinidades mais fortes, que facilmente identificamos quando visitamos esses espaços de diálogo e de partilha entre os jovens.

\section{CONCLUSÕES}

Neste artigo, procurámos discutir a forma como o espaço web pode promover a leitura de literatura infantil e juvenil e potencia a criação e a partilha destas leituras em diversas comunidades interpretativas. Num primeiro momento, problematizámos o lugar da literatura infantil e juvenil na Academia, tendo em conta a longa história e o extenso caminho trilhado por esta matriz literária, até ser reconhecida como sendo fundamental na formação das crianças e dos jovens e na sua entrada no mundo da Literatura e da Cultura.

Em seguida, tentámos compreender como a social web pode ter um papel relevante na configuração de novos públicos leitores. De facto, se por um lado assistimos à dispensa do mediador de leitura tradicional, por outro deparamo-nos com uma aproximação real e efetiva entre os autores e os seus leitores, manifestada num diálogo 
entre ambos, possibilitado pelas inúmeras ferramentas do ciberespaço. De algum modo, o mediador de leitura tradicional é agora substituído pelo autor e por uma eficaz partilha de leituras entre os jovens leitores e entre estes e os autores. É também notória a forma como os próprios autores procuram agora ir ao encontro dos "novos" espaços onde os jovens leitores "vivem". Na verdade, nas salas de chats, blogues, páginas no facebook, todos estes intervenientes trocam opiniões, emoções, afetos, que certamente impelem para outras profícuas leituras.

Estas ferramentas, pela sua interatividade, abrem a porta a novos públicos leitores que se por um lado saltam de aplicação em aplicação, por outro acedem mais facilmente à literatura, pelo apelo do hipertexto e do hipermédia. Em simultâneo, o contexto interativo da web 2.0, alimentado por esta motivação dos mais jovens, nativos digitais, para a comunicação online com os seus pares, faz com que a dimensão social da leitura assuma hoje um valor redobrado. Dificilmente se poderá negar a importância que estas comunidades literárias podem ter no incremento da leitura, criando sinergias entre os ambientes impresso e digital.

Assistimos, atualmente, à disseminação do fenómeno literário numa escala global, acompanhada pelo uso 
abundante das redes sociais, que enriquecem as ligações entre livros e leitores. E a literatura para crianças e jovens tem igualmente aproveitado as dinâmicas que se têm estabelecido no mundo digital.

\section{REFERÊNCIAS:}

Beagley, D. (2012). Blurring the Boundaries: the changing i-discourse of children's literature, The Looking Glass: New Perspectives on Children's Literature, 16(2). In http://www.the-looking-glass.net/index.php/tlg/ article/view/317/314 Acesso em outubro/2014.

Bringue, X. \& Sábada, C. (2011). Menores y redes sociales. Madrid: Foro Generaciones Interactivas.

Cervera, J. (1992). Teoría de la literatura infantil (2a ed.). Bilbao: Mensajero / Universidad de Deusto.

Dresang, E. T. (2008). Radical change revisited: Dynamic digital age books for youth. Contemporary Issues in Technology and Teacher Education, 8(3), 294-304.

Griffith, J. \& Frey, C. (1992) On Teaching the Canon of Children's Literature. In G. E. Sadler (Ed.), Teaching Children's Literature. Issues, Pedagogy, Resources (p.22-31). New York: The Modern Language Association of America.

Hunt, P. (Ed.) (1992). Literature for Children. Contemporary Criticism. London and New York: Routledge.

Lluch, G. \& Acosta, M. (2012). Conversaciones sobre lecturas en la Web 2.0: el caso de Laura Gallego. Análisis discursivo de conversaciones virtuales entre adolescentes. In J. Díaz Armas (Ed.), Lecturas para el nuevo siglo (p.37-52). La Laguna: Servicio de Publicaciones de la Universidad de La Laguna.

. \& Sánchez, S. (2013). Los retos de lectura. Reto Delirium, Pandemonium y Requiem. In http://blog.smconectados.com/2013/07/15/ los-retos-de-lectura-reto-delirium-pandemonium-y-requiem/ Acesso em 
outubro/2014.

Machado, A. M. \& Montes, G. (2003). Literatura Infantil. Creación, Censura y Resistencia. Buenos Aires: Editorial Sudamericana.

Martín-Barbero, J. \& Lluch, G. (Ed.) (2011). Lectura, escritura y desarrollo en la sociedad de la información. Bogotá: Cerlalc-Unesco. In http://cerlalc. org/publicacion/proyecto-lectura-escritura-y-desarrollo-en-la-sociedadde-lainformacion/Acesso em outubro/2014.

Nikolajeva, M. (1995). Children's Literature as a Cultural Code: A Semiotic Approach to History. In M. Nikolajeva (Ed.) Aspects and Issues in the History of Children's Literature (p. 39-48). Westport - London: Greenwood Press. Nodelman, P. (2008). The Hidden Adult. Defining Children's Literature. Baltimore: The Johns Hopkins University Press.

Otero, M. (2014). El boom de los clubs de lectura en internet. In http:// www.elconfidencial.com/cultura/2014-05-04/el-boom-de-los-clubs-delectura-en-internet 123055/ Acesso em outubro/2014.

Pereira, C. S. (2007). O affaire da literatura infantil e juvenil. In F. Azevedo (Coord.) Imaginário, Identidades e Margens. Estudos em torno da Literatura Infanto-Juvenil (p. 66-76). V. N. Gaia: Edições Gailivro.

Sánchez García, S.; Lluch Crespo, G. \& del Río Toledo, T. (2013). La lectura al web 2.0. Estudi de cas: els blogs en el Reto Delirium. @tic. Revista d'Innovació Educativa. (n.10). DOi: 10.7203/attic.10.1783. In http://ojs. uv.es/index.php/attic/article/view/1783/1996 Acesso em outubro/2014. Shavit, Z. (2003). Poética da Literatura para Crianças. Lisboa: Caminho. Townsend, J. R. (1980). Standards of Criticism for Children's Literature. In N. Chambers (Ed.), The Signal Approach to Children's Books (p.193-207). London: Krestel Books.

Unsworth, L. (2003). Reframing research and literacy pedagogy relating to $C D$ narratives: Addressing 'radical change' in digital age literature for children. Issues in Educational Research, 13(2), 55-70. In http://www.iier. org.au Acesso em outubro/2014.

. (2008). Multiliteracies, E-literature and English Teaching. 
Language and Education, 22:1, 62-75. DOI: 10.2167/le726.0.

Fernando Azevedo é docente do Instituto de Educação da Universidade do Minho, onde é o responsável pela regência de unidades curriculares de pós-graduação nas áreas da Literatura Infantil e Juvenil e Formação de Leitores. É Doutor em Ciências da Literatura e membro do Centro de Investigação em Estudos da Criança (CIEC), integrando igualmente o Observatório de Literatura Infanto-Juvenil (OBLIJ) e a Rede Internacional de Universidades Leitoras (RIUL). Pertence à Comissão de Especialistas do Plano Nacional de Leitura. Possui obras publicadas nos domínios da hermenêutica textual, literatura infantil e formação de leitores.

Ângela Balça é Professora Auxiliar no Departamento de Pedagogia e Educação da Universidade de Évora. É Licenciada em Línguas e Literaturas Modernas - Estudos Portugueses, pela Universidade Nova de Lisboa e Doutorada em Ciências da Educação pela Universidade de Évora. Em 2010, foi Professora Visitante na Universidade Estadual Paulista, São Paulo, Brasil. É Coordenadora, em Portugal, da Rede Internacional de Universidades Leitoras (RIUL). Orienta trabalhos académicos e publica nas áreas do Ensino da Língua Materna, Literatura Infantil e Bibliotecas Escolares.

Glória Bastos é Professora no Departamento de Educação e Ensino a Distância, na Universidade Aberta. Tem o Doutoramento em Estudos Portugueses, com uma tese sobre o teatro para crianças. Coordena o Curso de Mestrado em Gestão da Informação e Bibliotecas Escolares. Pertence ao Conselho Científico do Plano Nacional de Leitura e é coautora dos novos Programas de Português para o Ensino Básico (2009). 